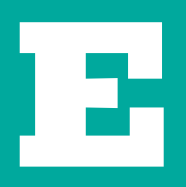

\title{
DIAS DE FÚRIA: CIDADES REBELADAS
}

| POR ROSA MARIA VIEIRA

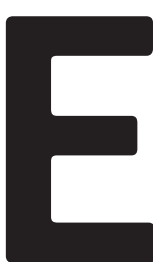

$\mathrm{m}$ meados de 2013, rebeliões em massa sacudiram as grandes cidades brasileiras. A partir dos protestos contra o aumento da tarifa do transporte público em São

Paulo, organizados pelo Movimento Passe Livre (MPL) e violentamente reprimidos, as revoltas alastraram-se de modo incontrolável pelo país, levando mais de um milhão de pessoas às ruas. Tão rápido quanto a expansão das manifestações - arregimentadas pelas redes sociais - , passou-se do repúdio à elevação do preço do transporte para pautas difusas, que iam da educação e saúde públicas de qualidade à negação do modelo político institucional de representatividade, aí incluídos partidos e parlamentares.

A ampla e espontânea incorporação de novos segmentos sociais nas manifestações, como setores conservadores da classe média pautados ideologicamente pela grande imprensa, fez com que surgissem apelos ao combate à corrupção, à redução da maioridade penal, além da hostilidade aos grupos de esquerda presentes nos protestos registrados em São Paulo.

A expansão das rebeliões levou, por fim, à vitória do MPL, pois, forçadas a recuar, autoridades municipais e estaduais acabaram revogando o aumento das tarifas. Porém, isso não foi suficiente para tirar as multidões das ruas. O Estado acuado viu-se forçado a incorporar em sua agenda política demandas por mobilidade urbana, verbas para educação, saúde e, até mesmo, reforma política.

Perplexidade e espanto perante a amplitude e o inesperado das explosões em massa foram reações compartilhadas por autoridades, mídia e cientistas sociais.

Como traduzir esses acontecimentos? Nos idos de junho, assistiu-se ao fim da apatia social e do "consenso" de classes que, durante as duas últimas décadas, imperaram no Brasil. Passados 20 anos do impeachment do ex-presidente Fernando Collor de Mello, o ressurgimento dos movimentos populares levou a política novamente às ruas, colocando uma nova geração de ativistas em ação e abrindo caminho a um ciclo de lutas sociais.

A amplitude e o ineditismo desses protestos - que fugiram das formas

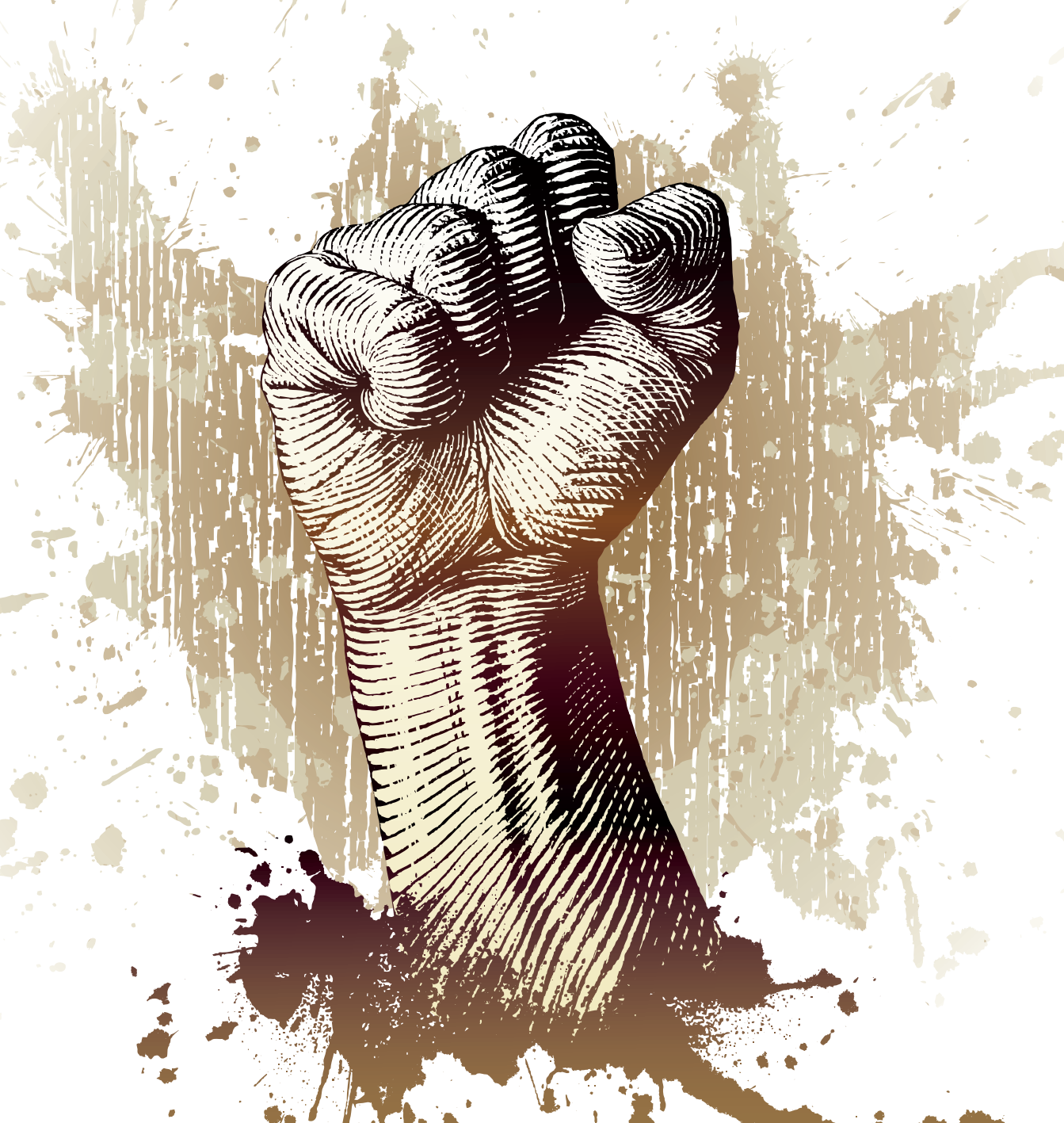




\section{O RESSURGIMENTO DOS MOVIMENTOS POPULARES LEVOU A POLÍTICA NOVAMENTE ÀS RUAS, COLOCANDO UMA NOVA GERAÇÃO DE ATIVISTAS EM AÇÃ́O E ABRINDO CAMINHO PARA UM CICLO DE LUTAS SOCIAIS}

clássicas de manifestações políticas, sem direção centralizada, palanques, sem a presença significativa de sindicatos e partidos, com pautas amplas e difusas - tornaram-se um desafio para o pensamento social. As profundas motivações dessas rebeliões ainda esperam respostas.

A fórmula consagrada: "É a economia, estúpido!" não satisfaz, porque, após décadas de estagnação, o Brasil voltou a crescer. Surfando na expansão da demanda mundial por commodities e abastecendo o extraordinário mercado chinês, o país chegou à condição de sétima economia mundial. A "decolagem" permitiu que o Brasil fosse apontado como mercado seguro para investidores estrangeiros e em condições de abrigar megaeventos esportivos.

Nesse contexto, foram postas em prática medidas de combate à fome $\mathrm{e}$ à pobreza, por meio do Bolsa Família e outros programas como PROUNI, PRONAF e Luz para Todos. Com vistas ao mercado interno, houve aumento real do salário mínimo e abertura de linhas de crédito ao consumidor, dentre as quais, o empréstimo consignado.

Investimentos em infraestrutura e estímulos à construção civil, projetos de aceleração do crescimento e o Minha Casa Minha Vida propiciaram não só o boom, como também a especulação imobiliária nas grandes cidades. Milhares de postos de trabalho foram criados, deixando-se para trás os altos níveis de desemprego.

Os índices estatísticos alimentaram o otimismo, pois, entre 2003 e 2011, a população em "condição de pobreza" caiu de 37,2 para 7,2\%, e o nível de desemprego, que atingiu $12,8 \%$ nas maiores regiões metropolitanas em 2003, passou para 5,8\% em 2012. Foi possível, afinal, anunciar o surgimento de uma "nova classe média".

Diante desse quadro, onde buscar as raízes da insatisfação explosiva? A resposta, apontada por alguns analistas, talvez esteja na perversa dialética da prosperidade econômica e desintegração social, na corrosão dos vínculos sociais no país, que evidenciam as dificuldades e os impasses da construção civilizatória no capitalismo flexível sob o impacto da globalização neoliberal.

No Brasil (recordista em concentração de renda), o trabalho sofreu profundas modificações. Autônomos, informais precarizados ou terceirizados estão no centro da expansão do emprego, submetidos ao assalariamento vulnerável e à ameaça permanente de desemprego. Para esses novos trabalhadores, que não contam com organização sindical nem representação política em partidos tradicionais, não existem vínculos e referências que, no passado, permitiam que se identificassem e se organizassem como classe social.

Fragmentação, dispersão e atomização atingem a todos. Tanto os de qualificação e ganhos mais elevados segmentos da classe média lançados na precariedade (jornalistas, bancários, publicitários, professores universitários) - , quanto os mais vulneráveis e mal remunerados (motoboys, operadores de telemarketing, faxineiros). Para esses, "sem partido" e "sem sindicato", encontra-se à disposição o arsenal ideológico, conservador e individualista, do evangelho da prosperidade ou do empreendedorismo de resultados, com miragens de consumo e validação da luta pela sobrevivência do mais apto.

As grandes cidades brasileiras que acolhem a todos não o fazem da mesma forma. A especulação imobiliária empurrou a força de trabalho barata rumo às periferias, onde se formaram as "cidades ilegais", tão miseráveis quanto seus moradores. Aí, serviços públicos básicos não existem, ou não funcionam, e a presença do Estado limita-se à violência policial. As grandes distâncias do trabalho precisam ser vencidas pelo transporte insuficiente, caro e de má qualidade.

As grandes metrópoles transformaram-se em um inferno. A "imobilidade urbana" gerada pela prioridade ao automóvel, a violência, a degradação ambiental e os serviços públicos escassos compõem o sofrimento de cada dia. Para os informalizados, o martírio urbano justapõe-se à humilhação social dos "diferenciados".

Milhões de vidas sem esperança e utopia. Nenhum futuro além do consumo. Anonimato e invisibilidade na sociedade do espetáculo. Direitos do consumidor no lugar de direitos sociais. Multidões em fúria. Isso vai se repetir até o desalento se traduzir em projeto...

ROSA MARIA VIEIRA > Professora da FGV-EAESP > rosa.vieira@fgv.br 